Acoustical Imaging

Volume 29 


\title{
Acoustical Imaging
}

\author{
Recent Volumes in This Series:
}

Volume 11 Proceedings of the Eleventh International Symposium May 4-7, 1981, edited by John P. Powers

Volume 12 Proceedings of the Twelfth International Symposium July 19-22, 1982, edited by Eric A. Ash and C. R. Hill

Volume 13 Proceedings of the Thirteenth International Symposium October 26-28, 1983, edited by M. Kavch, R. K. Mueller, and J. F. Greenleaf

Volume 14 Proceedings of the Fourteenth International Symposium April 22-25, 1985, edited by A. J. Berkhout, J. Ridder, and L. F. van der Wal

Volume 15 Proceedings of the Fifteenth International Symposium July 14-16, 1986, edited by Hugh W. Jones

Volume 16 Proceedings of the Sixteenth International Symposium June 10-12, 1987, edited by Lawrence W. Kessler

Volume 17 Proceedings of the Seventeenth International Symposium May 31-June 2, 1988, edited by Hiroshi Shimizu, Noriyoshi Chubachi, and Jun-ichi Kusibiki

Volume 18 Proceedings of the Eighteenth International Symposium September 18-20, 1989, edited by Hua Lee and Glen Wade

Volume 19 Proceedings of the Nineteenth International Symposium April 3-5, 1991, edited by Helmut Ermert and Hans-Peter Harjes

Volume 20 Proceedings of the Twentieth International Symposium September 12-14, 1992, edited by Yu Wei and Benli Gu

Volume 21 Proceedings of the Twenty-First International Symposium March 28-30, 1994, edited by Joie Pierce Jones

Volume 22 Proceedings of the Twenty-Second International Symposium September 3-7, 1995, edited by Piero Tortoli and Leonardo Masotti

Volume 23 Proceedings of the Twenty-Third International Symposium April 13-16, 1997, edited by Sidney Lees and Leonard A. Ferrari

Volume 24 Proceedings of the Twenty-Fourth International Symposium September 23-25, 1998, edited by Hua Lee

Volume 25 Proceedings of the Twenty-Fifth International Symposium March 19-22, 2000, edited by Michael Halliwel and Peter N. T. Wells

Volume 26 Proceedings of the Twenty-Sixth International Symposium September 9-12, 2001, edited by Roman Gr. Maev

Volume 27 Proceedings of the Twenty-Seventh International Symposium March 24-27, 2003, edited by W. Arnold and S. Hirsekorn

Volume 28 Proceedings of the Twenty-Eighth International Symposium March 20-23, 2005, edited by Michael P. André

Volume 29 Proceedings of the Twenty-Nineth International Symposium April 15-18, 2007, edited by Iwaki Akiyama

A Continuation Order Plan is available for this series. A continuation order will bring delivery of each new volume immediately upon publication. Volumes are billed only upon actual shipment. For further information please contact the publisher. 


\section{Acoustical Imaging Volume 29}

\section{Edited by}

\section{Iwaki Akiyama}

Shonan Institute of Technology, Kanagawa, Japan

Springer 


\section{Editor}

Iwaki Akiyama

Shonan Institute Technology

Faculty of Engineering

1-1-25 Tsujido-Nishikaigan

Fujisawa, Kanagawa-ken

251-8511 Japan

ISBN: 978-1-4020-8822-3

e-ISBN: 978-1-4020-8823-0

Library of Congress Control Number: 2008931481

(c) 2008 Springer Science+Business Media B.V.

No part of this work may be reproduced, stored in a retrieval system, or transmitted in any form or by any means, electronic, mechanical, photocopying, microfilming, recording or otherwise, without written permission from the Publisher, with the exception of any material supplied specifically for the purpose of being entered and executed on a computer system, for exclusive use by the purchaser of the work.

Printed on acid-free paper

$\begin{array}{lllllllll}9 & 8 & 7 & 6 & 5 & 4 & 3 & 2 & 1\end{array}$

springer.com 


\section{9th International Symposium on Acoustical Imaging}

Chairman: Iwaki Akiyama

\section{Executive Council}

Walter Arnold, Germany

Hua Lee, USA

Noriyoshi Chubachi, Japan

Roman Maev, Canada

Kenneth Erikson, USA

Joie P. Jones, USA

Piero Tortoli, Italy

\section{International Advisory Board}

Iwaki Akiyama, Japan

Michael Andre, USA

Walter Arnold, Germany

Jeff Bamber, United Kingdom

Noriyoshi Chubachi, Japan

Kenneth Erikson, USA

Helmut Ermert, Germany

Woon S. Gan, Singapore

James Greenleaf, USA

Joie P. Jones, USA

Hiroshi Kanai, Japan

Pierre Khuri-Yakub, USA
Hua Lee, USA

Sidney Lees, USA

Vadim M.Levin, Russia

Roman Maev, Canada

William O'Brien, USA

Patrick Rafter, USA

Daniel Rouseff, USA

Bernhard Tittmann, USA

Piero Tortoli, Italy

A.F.W. van der Steen, Netherlands

Glen Wade, USA

Peter N.T. Wells, United Kingdom

\section{Technical Program Committee}

Walter Arnold

Nobuyuki Endoh

Hiroyuki Hachiya

Joie P. Jones

Tomoo Kamakura

Hiroshi Kanai

Junichi Kushibiki

Kohji Masuda

Kentaro Nakamura
Akihisa Ohya

Yoshifumi Saijo

Tsuyoshi Shiina

Piero Tortoli

Takao Tsuchiya

Shin-ichiro Umemura

Oliver B. Wright

Kazushi Yamanaka 


\section{Local Organizing Committee}

Iwaki Akiyama

Kunihiro Chihara

Noriyoshi Chubachi

Nobuyuki Endoh

Hiroyuki Hachiya

Kazuhiko Hamamoto

Hideyuki Hasegawa

Tutomu Hoshimiya

Hiroshi Inoue

Takashi Itoh

Tomoo Kamakura

Naohisa Kamiyama

Hiroshi Kanai

Nobuki Kudo

Junichi Kushibiki

Mami Matsukawa

Kentaro Nakamura
Toshiaki Nakamura

Naotaka Nitta

Gosuke Ohashi

Akihisa Ohya

Yoshifumi Saijo

Yasutsugu Seo

Tsuyoshi Shiina

Chikayoshi Sumi

Yasuhito Takeuchi

Shin-ichiro Umemura

Shin-ichi Yagi

Akira Yamada

Yoshiki Yamakoshi

Katsuyuki Yamamoto

Kazushi Yamanaka

Masahide Yoneyama

Yoshiaki Watanabe 


\section{CONTENTS}

Preface XV

STRAIN IMAGING 1

Use of Radiation Force to Measure Arterial Properties

J.F. Greenleaf, X. Zhang, C. Pislaru. 3

Microscopic Measurement of Three-Dimensional Distribution of

Tissue Viscoelasticity

T. Shiina, M. Yoshida, M. Yamakawa, N. Nitta...

Strain Imaging for Arterial Wall with Translational Motion

Compensation and Center Frequency Estimation

H. Hasegawa, H. Kanai.

Near-Real-Time 3D Ultrasonic Strain Imaging

G. Treece, J. Lindop, A. Gee, R. Prager.

Dynamic Resolution Selection in Strain Imaging

J. Lindop, G. Treece, A. Gee, R. Prager.

A New Non-Invasive Ultrasonic Method for Measurements of

Longitudinal Length Alteration of the Arterial Wall - First

In Vivo Trial

M. Cinthio, A. R. Ahlgren, H.W. Persson, K. Lindström.

Evaluation of Tissue Motion Vector Measurement System

Utilizing Synthetic-Aperture Array Signal Processing for

Real-Time Elastography

S. Yagi, A. Sanuga, K. Tamura, M. Sato 45

Ultrasonic Imaging of Hemodynamic Force in Carotid Blood Flow

N. Nitta, K. Homma

Increasing Accuracy of Tissue Shear Modulus Reconstruction

Using Ultrasonic Strain Tensor Measurement

C. Sumi .59 
Pre-Clinical Experience with Full-Wave Inverse-Scattering for

Breast Imaging

M.P. André, C.H. Barker, N. Sekhon, J. Wiskin,

D. Borup, K. Callahan

High-Frequency Pulse-Compression Ultrasound Imaging with an Annular Array

J. Mamou, J.A. Ketterling, R.H. Silverman

Blood Flow Imaging in Maternal and Fetal Arteries and Veins

S. Ricci, G. Urban, P. Vergani, M. J. Paidas, P. Tortoli

Carotid Plaque Tissue Differentiation Based on Radiofrequency

Echographic Signal Local Spectral Content (RULES:

Radiofrequency Ultrasonic Local Estimators)

E. Biagi, S. Granchi, A. Luddi, L. Breschi, R. Facchini, A. Ricci,

L. Masotti

Cross-Sampling Measurement of Vocal-Fold Vibration

Using Ultrasound

O. Oshiro, S. Kamei, Y. Masuda, Y. Kuroda, T. Kuroda.

Pressure-Dependent Attenuation of Ultrasound Contrast Agents

N. Kudo, N. Hirao, K. Okada, K. Yamamoto

3-D Acoustic Imaging System with a Reflector and a Small Array

H. Taki, T. Sato.

New Method for Ultrasound Contrast Imaging Using

Frequency-Modulated Transmission

H. Ohuchi, N. Kamiyama, T. Kawagishi, T. Imamura,

T. Asanuma, H. Ishikura, S. Beppu

Ultrasonic Detection and Imaging of Brachytherapy Seeds

Based on Singular Spectrum Analysis

J. Mamou, E. J. Feleppa.

Evaluation of Post Wall Filter for Doppler Ultrasound Systems

T. Baba 
Combining Ultrasonic and Magnetic-Resonance Spectral Methods for Imaging Prostate Cancer E. Feleppa, S. Dasgupta, S. Ramachandran, J. Ketterling, A. Kalisz, C. Porter, M. Lacrampe, C. Isacson, S. Haker, C. Tempany

Radio Frequency Signal Analysis for Tissue Characterization of Coronary Artery: In Vivo Intravascular Ultrasound Study T. Iwamoto, Y. Saijo, A. Tanaka, E. S. Filho, S. Li, M. Yoshizawa

Tissue Thermal Property Reconstruction by Stopping Heating and Perfusion

C. Sumi, T. Uchida, T. Ooba, K. Inoue

ACOUSTICAL MICROSCOPY 161

New Generation of High Resolution Ultrasonic Imaging Technique for Advanced Material Characterization. Review R.Gr. Maev

Visualization of Acoustic Waves Propagating within a Single

Anisotropic Crystalline Plate with a Hybrid Acoustic Imaging Technique

C. Miyasaka, K.L. Telschow, J.T. Sadler, R.Gr. Maev

Ultrasonic Nano-imaging System for Medicine and Biology

Y. Saijo, N. Hozumi, K. Kobayashi, N. Okada, Y. Hagiwara,

H. Sasaki, E.d. S. Filho, T. Yambe

Elastic Changes of Capsule in a Rat Knee Contracture Model

Assessed by Scanning Acoustic Microscopy

Y. Hagiwara, E. Chimoto, A. Ando, Y. Saijo, E. Itoi

A Study of the Potential to Detect Caries Lesions at the White-Spot

Stage Using $\mathrm{V}(\mathrm{Z})$ Technique

E. Y. Bakulin, L. A. Denisova, R. Gr. Maev

Investigation of Human Nail Microstructure with Ultrasound

A.R. Maeva, E.Y. Bakulin, L.A. Denisova, R.Gr. Maev. 
NON-DESTRUCTIVE EVALUATION AND INDUSTRIAL APPLICATION

Ultrasonic Atomic Force Microscopy of Subsurface Defects

K. Yamanaka, K. Kobari, S. Ide, T. Tsuji

Quantitative Material Characterization and Imaging at Nanoscale

Using A New AFM Probe

F.L. Degertekin, M. Balantekin, A.G. Onaran

Non-Destructive Testing of Die-Casting Components of

Non-Ferrous Metals for Surface-Near Porosity by

High-Frequency Ultrasound

S. Hirsekorn, U. Rabe, D. Bruche, N. Grov, T. Kinzler, W. Arnold .....223

Detection of Harmonic Components Generated from Crept Metal

Rod Using a Double-Layered Piezoelectric Transducer System

M. Fukuda, M. Nishihira, K. Imano.

Observation of Two-Dimensional Spatial Distribution of Plane Crack

Tips with Low-Power Pulsed Laser

H. Fujii, T. Miyake, M. Matsukawa.

Reconstruction of the Ultrasonic Image by the Combination of

Genetic Programming and Constructive Solid Geometry

M. Yamagiwa, F. Sugimoto, M. Yoneyama

Source Localization by Simulation of Time Reversal Wave and its

Resolution Improvement with Deconvolution Technique

N. Wakatsuki, K. Mizutani.....

COMPONENTS AND SYSTEMS

Nonlinear Multibeam Ultrasonic Imaging

I. Akiyama, N. Yoshizumi, A. Ohya, S. Saito

Dynamic-Receive Focusing with High-Frequency Annular Arrays

J.A. Ketterling, J. Mamou, R.H. Silverman....

Fully Fiber Optic Ultrasonic Probes for Virtual Biopsy

E. Biagi, S. Cerbai, P. Gambacciani, L. Masotti 
High Resolution Ultrasonic Method for 3D Fingerprint

Representation in Biometrics

R. Gr. Maev, E.Y. Bakulin, E.Y. Maeva, F.M. Severin

Optoacoustic Imaging

M. Frenz, M. Jaeger, A. Gertsch, M. Kitz, D. Schweizer

New Imaging Method by Using Ultrasound Velocity Change

Caused by Optical Absorption

H. Horinaka, T. Matsunaka, N. Nakamura, T. Mukaiyama,

S. Kawakami, M. Kawasaki, K. Wada.

Range Measurement Using Ultrasound FMCW Wave

M. Kunita, T. Miki, I. Arai.

Direct Visualization of High-Intensity Focused Ultrasonic Field

Using Light-Emitting Diodes and Piezoelectric Elements

K. Nakamura, H. Ogura, T. Sugimoto.

Sensor Signal Processing for Ultrasonic Sensors Using Deleta-Sigma

Modulated Single-Bit Digital Signal

S. Hirata, M.K. Kurosawa, T. Katagiri

A Method of Indoor Target Detection Using M-Sequence

Acoustic Signal

T. Yamaguchi, K. Nishihara, H. Matsuo, Y. Wang, M. Hashimoto,

H. Hachiya

GEOPHYSICS AND UNDERWATER IMAGING

Comparison of Some Aspherical Curved Surfaces of a Single

Biconcave Acoustic Lens System for Ambient Noise Imaging

K. Mori, H. Ogasawara, T. Nakamura.

Underground Imaging Using Shear Waves

H. Kawasaki, T. Sugimoto.

High-Speed Vortex Wind Velocity Imaging by Acoustic

Tomography

H. Li, T. Ueki, K. Hayashi, A. Yamada 
Optical Observation of Two Collapsing Bubbles Adhering to

a Quartz Wall

K. Yoshida, S. Nakatani, Y. Watanabe

Optical Observation of a Collapsing Bubble Adhering to a

Piezoelectric Transducer Surface under Ultrasound Field

S. Nakatani, K. Yoshida, Y. Watanabe

Visco-Elastic Models for Soft Tissues

S. Leeman, J. Jones

Eigenvalue Imaging of A0-Mode Lamb Wave Field Based on

Spatio-Temporal Gradient Analysis

K. Teramoto, A. Uekihara

Vector Theory of Ultrasonic Imaging

W. S. Gan.

Gauge Invariance Approach to Acoustic Fields

W. S. Gan.

MEDICAL IMAGE ANALYSIS

Reproducibility of Image Analysis for Breast Ultrasound

Computer-Aided Diagnosis

M. Galperin, M.P. Andre, C.H. Barker, L.K. Olson, M. O'Boyle,

K. Richman, L. Mantrawadi.

Wavelet Restoration of Three-Dimensional Medical Pulse-Echo

Ultrasound Datasets in an EM Framework

J. Ng, H. Gomersall, R. Prager, N. Kingsbury, G. Treece, A. Gee

Synthetic Aperture Focusing of Echographic Images by Means of

Pulse Compression

E. Biagi, L. Masotti, L. Pampaloni, M. Scabia.

ML Estimation for Acoustical Image Deblurring A. Palladini, N. Testoni, L.D. Marchi, N. Speciale 
Three-Dimensional Imaging by Using Singularity-Spreading

Phase Unwrapping Method

T. Nishino, R. Yamaki, A. Hirose.

Indication of Probe-Axis Angle by Extracting Wall Motion of

Heart to Assist in Obtaining Long- and Short-Axis Views on

Echocardiography

K. Masuda, H. Matsuura, R. Takahashi.

Detection of Right Atrium Movement in Thrombi Flow

Measurement

M. Aoki, T. Yamaguchi, H. Hachiya.

Study of Probe Navigation Algorithm for Echocardiography to

Acquire Standard Cross Section

T. Imai, H. Inoue, T. Sakai, K. Masuda.

Development of CAD System for Diffuse Disease Based on

Ultrasound Elasticity Images

M. Yamazaki, T. Shiina, M. Yamakawa, H. Takizawa, A. Tonomura, T. Mitake.

FDTD METHOD AND OTHER NUMERICAL SIMULATIONS

FDTD Calculation of Linear Acoustic Phenomena and its Application to Architectural Acoustics and Environmental Noise Prediction

S. Sakamoto

Quantitative Assessment of Tubes and Rods: Comparison of

Empirical and Computational Results

J.J. Kaufman, G.M. Luo, B. Blazy, R.S. Siffert.

Heated Temperature Imaging by Absorption of Ultrasound

C. Yamaya, H. Inoue

Time Domain Analysis of Sound Propagation in Shallow Water with Transitional Layer

T. Tsuchiya, S. Matsumoto, N. Endoh

Visualization of Temperature Distribution in Cylindrical Cavity

Using Sounds Reflected from Internal Surface

A. Minamide, K. Mizutani, N. Wakatsuki. 
Real Time Sound Field Simulator Using Field Programmable Gate Array Device

T. Tsuchiya, E. Sugawara, Y. Inoguchi

Two-Dimensional Numerical Analysis of Acoustic Field Using the Constrained Interpolation Profile Method S. Oh, K. Okubo, T. Tsuchiya, N. Takeuchi. 


\section{PREFACE}

The 29th International Symposium on Acoustical Imaging was held in Shonan Village, Kanagawa, Japan during April 15-18, 2007. Despite the unusually cold and rainy weather for Shonan Area in April, the symposium was a great success owing to lively discussions among enthusiastic speakers and audiences, which assured us the future prosperity of the field of Acoustical Imaging. There were more than 100 participants and 83 presentations were given by delegates from about ten countries, e.g. Japan, USA, Canada, Italy, England, and Germany. I would like to express my gratitude to the following six invited speakers, who presented appreciative speeches at the symposium: Prof. James F. Greenleaf, Prof. Roman G. Maev, Prof. Kazushi Yamanaka, Prof. F. Levent Degertekin, Dr. Shin'ichi Sakamoto and Dr. Chiaki Miyasaka. Like its predecessors in the series this Volume 29 contains an excellent collection of papers, including the six invited speeches, presented in nine major categories:

- Strain Imaging

- Biological and Medical Applications

- Acoustic Microscopy

- Non-Destructive Evaluation and Industrial Applications

- Components and Systems

- Geophysics and Underwater Imaging

- Physics and Mathematics

- Medical Image Analysis

- FDTD method and Other Numerical Simulations

The 29th International Symposium on Acoustical Imaging owes its success to so many people that it is difficult to list all the names. However, I would like to acknowledge particularly for assisting me in the organization of the symposium: Prof. Noriyoshi Chubachi, Prof. Junichi Kushibiki and Prof. Hiroshi Kanai, who helped to realise this symposium in Japan, Mrs. Michiko Ohse and Mrs. Ayako Kamimura, who performed the preparations and arrangements, Dr. Akihisa Ohya and Dr. Tadashi Yamaguchi, who gave full assistance during the symposium itself, Prof. Michael P. Andre, the chairman of AI28, who gave instructive advices in organizing the symposium, and Prof. Yohichi Suzuki, the former president of Acoustic Society of Japan, who kindly agreed to co-organizing the symposium. Thanks also to Prof. Yoshiaki Watanabe, for his valuable advices. 